\title{
Jenis-jenis gigitiruan dukungan implan Implant-supported dentures
}

\author{
Poedji Rahajoeningsih, Rosida Manurung \\ Bagian Prostodonsia \\ Fakultas Kedokteran Gigi Universitas Padjajaran \\ Bandung, Indonesia
}

\begin{abstract}
Dental implants, or completely said as dental implant bodies, function as analogues of tooth roots, achieving a union directly with jawbone following their insertion into a prepared socket in the bone. Implant system have three basic components, namely the dental implant body that is lying in the jawbone, abutment that lies on the jawbone and the prosthesis. Dental implants may stabilize a removable prosthesis, complete or partial overdentures, and or support and stabilize a fixed prosthesis. In designing implant-supported removable prostheses, there are three forms of anchorage frequently used, namely bar/sleeve (clip) joints which links two or more implants, ball/cap anchorages applied individually to two or more isolated implants, and magnets/magnetic keepers. Implant-supported fixed prosthesis is either screwed to or cemented on to the abutment.
\end{abstract}

Key words: implant, removable denture, fixed denture

\begin{abstract}
ABSTRAK
Implan dental, atau lebih lengkap disebut dental implant body, akan menyatu dalam tulang, berfungsi menggantikan akar gigi. Implan dental dapat menstabilkan baik gigitiruan lepasan maupun gigitiruan cekat. Sistem implan mempunyai 3 komponen dasar yaitu dental implant body yang umum disebut implan, yang tertanam dalam tulang, bagian abutment merupakan bagian di atas tulang, dan komponen ketiga adalah bagian prostesis. Terdapat 2 pilihan gigitiruan dengan dukungan implan, yaitu gigitiruan lepasan dan gigitiruan cekat. Pada rencana pembuatan gigitiruan lepasan dukungan implan, sering digunakan tiga macam anchorage, yaitu bar/sleeve (clip) joint yang akan menghubungkan 2 atau lebih implan, ball/cap anchorage, dan magnet/magnetic keeper. Sedangkan gigitiruan cekat dukungan implan, merupakan gigitiruan yang bersandar pada implan dengan sistem sekrup atau dengan penyemenan.
\end{abstract}

Kata kunci: implan, gigitiruan lepasan, gigitiruan cekat

Koresponden: Rosida Manurung, Bagian Prostodonsia, Fakultas Kedokteran Gigi Universitas Padjajaran. Jl. Sekeloa Selatan No.1, Bandung, Indonesia. E-mail: manurung.rosida@gmail.com.

\section{PENDAHULUAN.}

Implan dental akan menyatu dalam tulang, akan berfungsi menggantikan akar gigi. Implan dental dapat menstabilkan baik gigitiruan lepasan maupun gigitiruan cekat. ${ }^{1}$

Sistem implan mempunyai tiga komponen dasar (gambar 1), yaitu dental implant body yang biasa disebut implan atau fixture. Bagian ini yang tertanam dalam tulang, sehingga berfungsi sebagai gigi alami. Abutment merupakan bagian implan yang berada di atas tulang dan menghubungkan implant body dengan suprastruktur. Komponen ketiga adalah suprastrukturnya, yaitu gigitiruannya sendiri.

Sebelum dilakukan penanaman implan, jenis gigitiruan dan disain prostetiknya lebih dahulu harus ditentukan supaya jenis dan letak implannya sesuai dengan jenis gigitiruan yang direncanakan. Terdapat dua jenis gigitiruan sebagai suprastruktur dukungan implan, yaitu gigitiruan cekat dan gigitiruan lepasan. ${ }^{1-3}$ Gigitiruan cekat dukungan implan bersandar pada implan dengan dua cara,

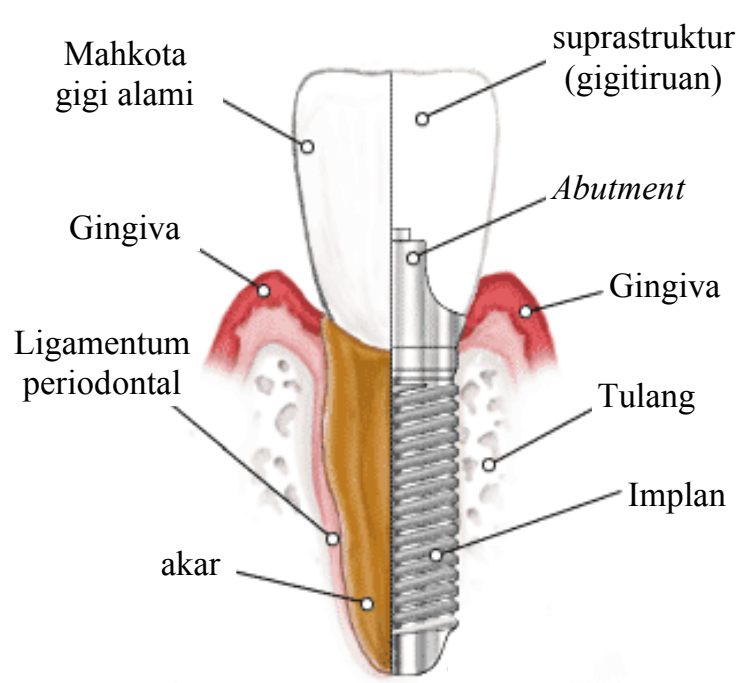

Gambar 1 Perbandıngan 1mplan dental dengan gigi alami dan bagian-bagiannya

yaitu dengan sistem sekrup atau dengan sistem penyemenan. Sementara untuk gigitiruan lepasan dukungan implan, terdapat 3 macam penjangkaran yaitu bar/sleeve (clip) joint akan menghubungkan 
dua atau lebih implan, ball/cap anchorage, dan magnet.

Adanya beberapa pilihan dalam hal mendesain jenis gigitiruan yang dapat didukung oleh implan, maka pada artikel ini akan dibahas mengenai jenis-jenis gigitiruan dukungan implan.

\section{TINJAUAN PUSTAKA}

Implan dapat dipasang dengan 3 sistem, yaitu sistem tertutup, sistem terbuka, dan sistem immediate restoration (Gambar 2). Sistem tertutup disebut juga closed mucosal system atau sistem dua tahap. Pada sistem ini, seluruh panjang implan dari apikal sampai pundak implan tertanam setinggi tulang alveolaris. Flap mukoperiosteal dijahit di atas implan. Implan dibiarkan selama 1,5-6 bulan tergantung lokasinya, kualitas tulang dan produk pabrik pembuatnya. Tujuannya supaya terjadi integrasi implan dental dengan tulang.

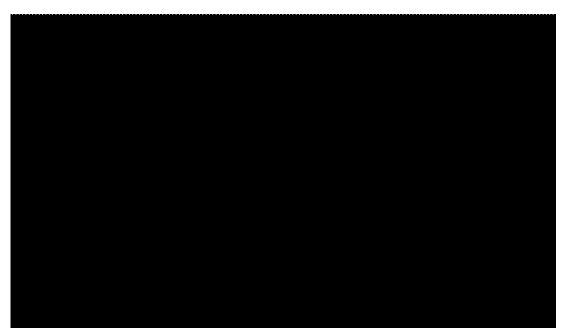

Gambar 2 Sistem pemasangan implan; A sistem tertutup atau 2 tahap, B sistem terbuka atau 1 tahap, dan $\mathbf{C}$ sistem immediate restoration
Untuk pemasangan komponen sekunder, jaringan mukosa harus dibuka lagi, yang disebut operasi kedua.

Sistem terbuka, disebut juga transmucosal system atau sistem satu tahap. Pada sistem ini implan tidak terpendam seluruhnya, sebagian menonjol dari permukaan mukosa dan flap berada di sekitar leher implan. Komponen sekunder dapat langsung dipasang tanpa membuka jaringan mukosa, jadi tidak ada operasi kedua. Yang ketiga, sistem immediate restoration. Sistem ini satu tahap dan sekaligus pemasangan abutment dan suprastruktur tanpa kontak dengan gigi antagonis. ${ }^{4}$

\section{Gigitiruan cekat dukungan implan}

Gigitiruan cekat dukungan implan ada yang berupa single tooth implant restoration, fixed cementable prosthesis, fixed-detachable prosthesis, hybrid bridge fixed-detachable prosthesis ${ }^{2,3}$

Single tooth implant restoration atau single crown adalah jenis gigitiruan dukungan implan yang menggantikan satu gigi yang hilang. Single-tooth prosthesis dapat berupa implant-borne crown, yang berdiri sendiri, tidak meliputi gigi sebelahnya (Gambar 3). Single restoration dapat juga meliputi gigi di sebelahnya karena dukungan yang kurang baik dengan semiprecision attachment pada satu atau lebih gigi di sebelah menyebelahnya (Gambar 4).

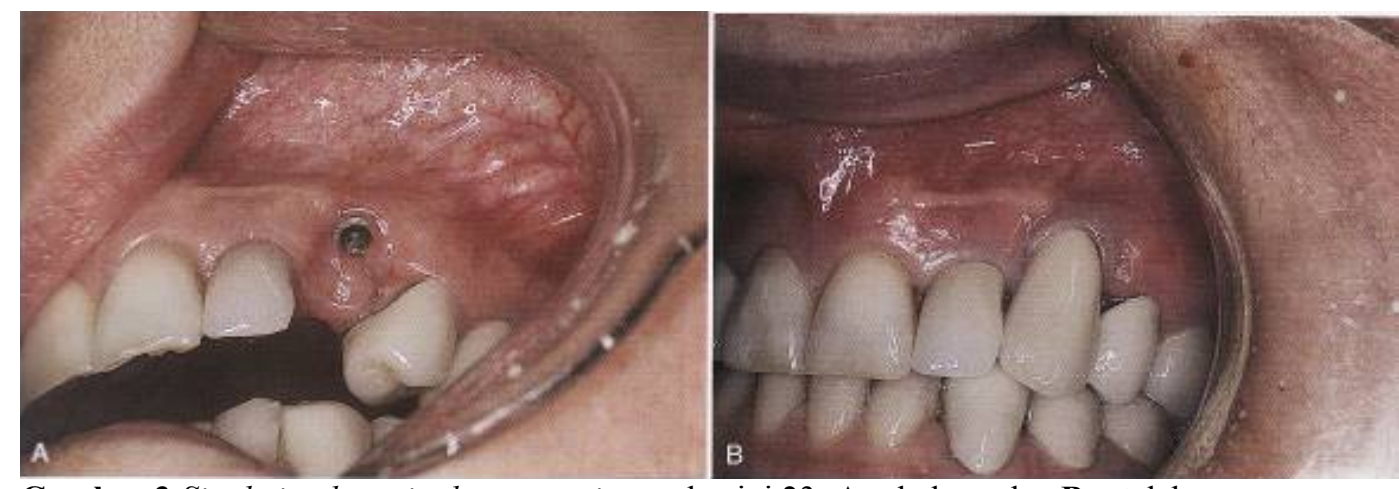

Gambar 3 Single implant single restoration pada gigi 23; A sebelum, dan B setelah pemasangan suprastruktur (Sumber: Singh PP, Cranin AN. Atlas of oral implantology. $3^{\text {rd }}$ Ed.; 2010. p. 59-67; 318-70). ${ }^{3}$
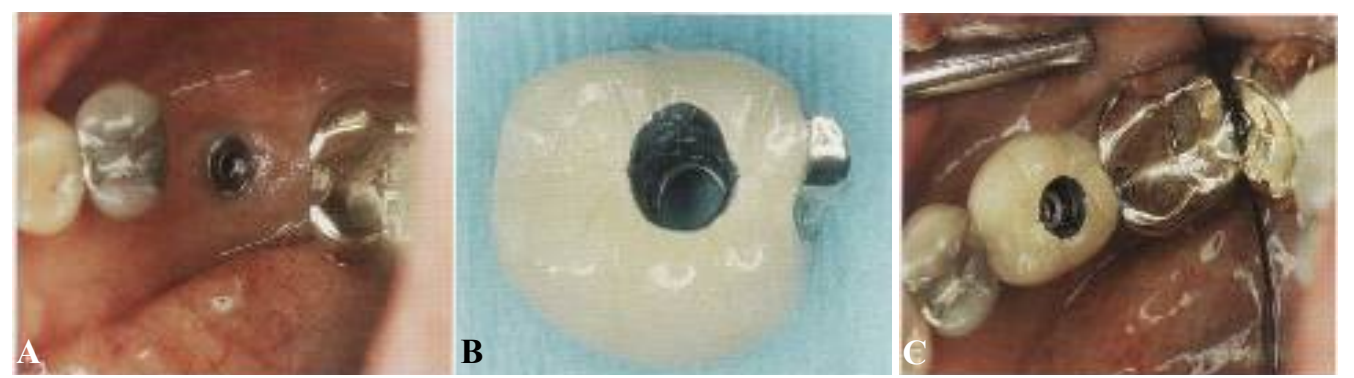

Gambar 4A Single implant, B single crown dengan semiprecision, C single crown di dalam mulut (Sumber: Singh PP, Cranin AN. Atlas of oral implantology. $3^{\text {rd }}$ Ed.; 2010. p. 59-67; 318$70)^{3}$ 

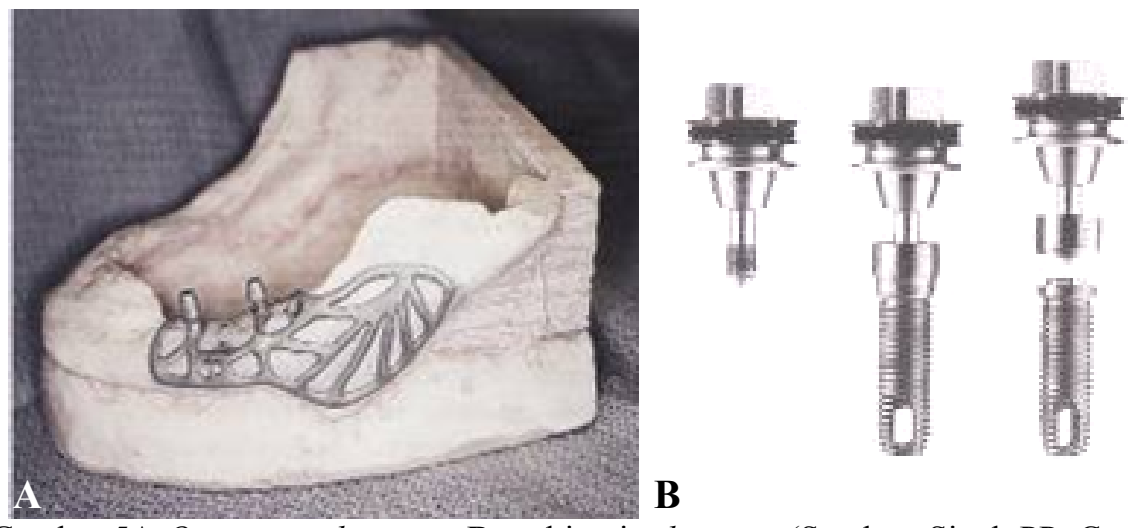

Gambar 5A One piece abutment, B multi unit abutment (Sumber: Singh PP, Cranin AN. Atlas of oral implantology. $3^{\text {rd }}$ Ed.; 2010. p. 59-67; 318-70). ${ }^{3}$

Abutment dapat berupa single unit (Gambar $5 \mathrm{~A}$ ), yaitu badan implan bersatu dengan abutmentnya. Selain single unit ada juga yang berupa 2 pieces atau 3 pieces (Gambar 5B), yaitu masing masing dihubungan dengan sekrup. Abutment dapat berupa sediaan buatan pabrik, atau dapat juga dibuat sendiri di laboratorium. Single unit implant dapat berupa blade, subperiosteal dan Zimmer's one-piece root form implant, abutment bersatu dengan body implant. Sedangkan retensi mahkota pada abutment dapat dengan semen atau dengan sekrup. $^{2,3}$

Fixed cementable prosthesis merupakan prostesis cekat dengan retensi dari penyemenan mahkota ke abutment (gambar 6).

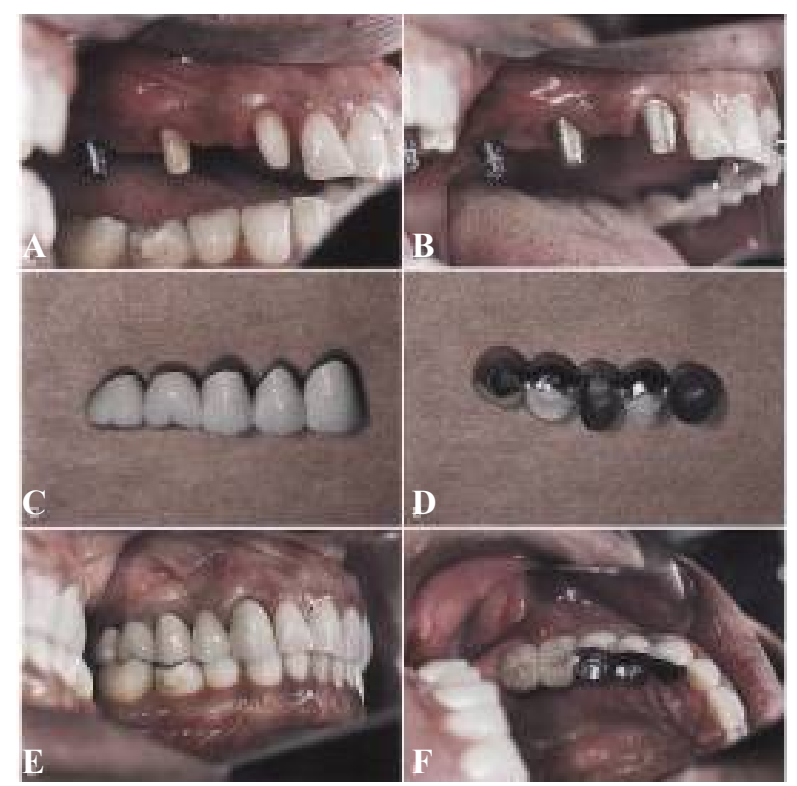

Gambar 6 Fixed cementable prosthesis; A implant abutment yang dibuat sejajar dengan 2 abutment gigi alami, B abutment gigi alami dengan coping, C PFM bridge, D pandangan servikal, $\mathbf{E}$ gigitiruan jembatan 5 unit telah disemen, F pandangan oklusal (Sumber: Singh PP, Cranin AN. Atlas of oral implantology. $3^{\text {rd }}$ Ed.; 2010. p. 59-67; 318-70. $)^{3}$
Fixed-detachable prosthesis banyak disukai pasien karena penampilan yang lebih alami, terutama pasien dengan garis bibir yang tinggi pada saat tersenyum. Walaupun fixed detachable superstructures sebenarnya dapat dipasang dengan sistem 1 tahap yang disebut dengan transmusosal system apalagi pada subperiosteal dan transosteal implants, namun biasanya dilakukan dengan 2 tahap yang disebut dengan closed mucosal system. Jenis fixed detachable prosthesis dapat dirancang dalam 2 bentuk dasar, yaitu traditional high-water hybrid design dari Branemark, dan unit type atau jenis anatomic fixed bridge prosthesis, yang hanya dapat dibuat apabila pada saat pemasangannya, implan ditempatkan pada posisi yang akurat dengan gigi alami ${ }^{2,3}$ (Gambar 7).
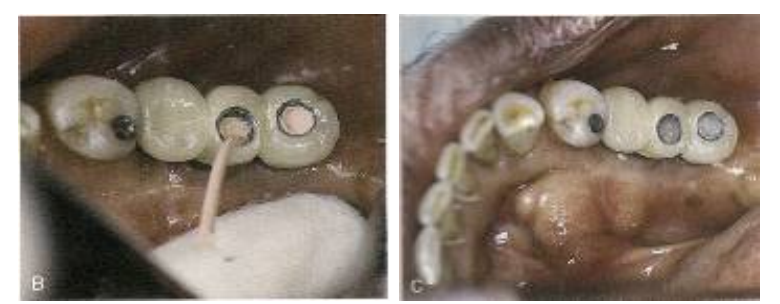

Gambar 7 Fixed detachableprostheses (Sumber: Singh PP, Cranin AN. Atlas of oral implantology. $3^{\text {rd }}$ Ed.; 2010. v. 59-67: 318-70). ${ }^{3}$

Hybrid bridge fixed-detachable prosthesis adalah fixed bridge yang dibuat pada kerangka logam yang berbentuk bar dengan retensi sekrup pada gigitiruannya. Desain ini biasa dirancang pada rahang yang sudah tak bergigi sama sekali. Prognosis baik apabila rahang yang berlawanan adalah gigitiruan lengkap atau hybrid bridge juga. Mandibular hybrid bridge memerlukan 5 implan. Sedangkan maxillary hybrid bridge memerlukan minimal 6 implan. Makin banyak implan yang digunakan pada rahang atas, bahkan bisa sampai 12 , makin baik prognosisnya., ${ }^{2,3}$ (Gambar 8). 

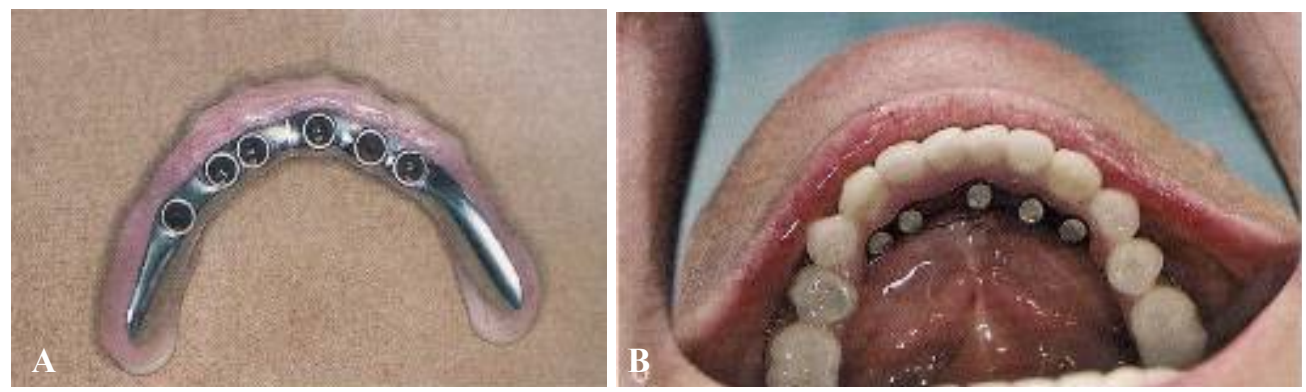

Gambar 8A Hybrid bridge fixed detachable prostheses, B Hybrid bridge fixed detachable prostheses di dalam mulut (Sumber: Singh PP, Cranin AN. Atlas of oral implantology. $3^{\text {rd }}$ Ed.; 2010. p. 59-67; 318-70.). ${ }^{3}$
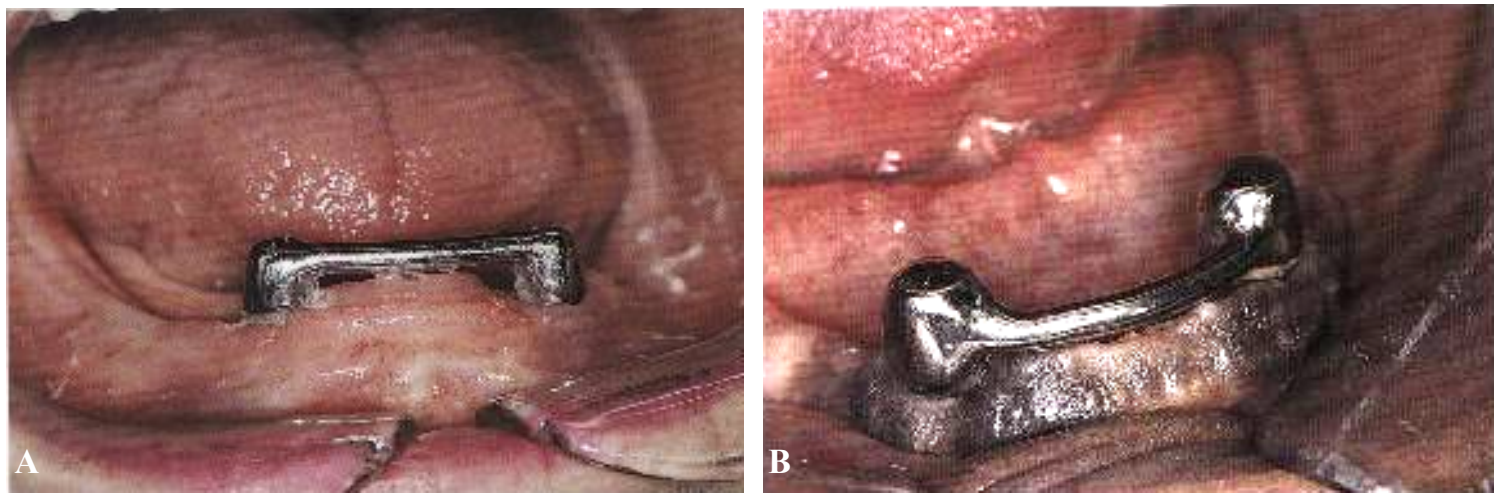

Gambar 9A Bar lurus menghubungkan 2 implan, B bar lengkung menghubungkan 2 implan (Sumber:

Singh PP, Cranin AN. Atlas of oral implantology. $3^{\text {rd }}$ Ed.; 2010. p. 59-67; 318-70). ${ }^{3}$

\section{Gigitiruan lepasan dukungan implan}

Overdenture merupakan jenis gigitiruan yang banyak digunakan pada sistem dukungan implan. Overdenture diklasifikasi menjadi 2 jenis, yaitu yang didukung oleh jaringan lunak dan implan atau gigi, dan yang murni didukung oleh implan. Overdenture adalah suatu gigitiruan penuh atau sebagian lepasan yang menutupi dan bersandar pada satu atau lebih gigi alami, akar gigi dan atau implan dental. Gigitiruan overdenture diketahui dapat menghambat proses resorpsi berlanjut, sehingga diperoleh retensi dan stabilisasi yang maksimal.

Overdenture yang merupakan gigitiruan yang didukung oleh jaringan lunak dan implan atau gigi, dan retensi pada implan atau gigi. Retensi pada implan atau gigi, dapat dibuat pada bar yang bentuknya lurus yang menghubungkan antara implan (Gambar 9A).

Splinting implan dengan bar diantara dua implan ini akan lebih menguntungkan dari pada retensi dari masing masing implan yang berdiri sendiri. Dengan konstruksi semacam itu dilengkapi dengan klip internal yang dibuat untuk retensi pada bar, klip dapat berotasi pada bar dan menyebabkan gigitiruan di bagian posterior didukung oleh jaringan lunak. Hal ini yang menyebabkan gigitiruan didukung oleh implan dan jaringan lunak. Bila karena alasan tertentu, bar yang dibuat diantara implan tidak dapat dibuat lurus tetapi melengkung, maka klip pada overdenture tidak dapat berotasi pada bar, sehingga gigitiruan di bagian posterior dapat mengungkit bagian bar dan implan (Gambar 9B).

Overdenture yang menggunakan ball attachment. Menurut Mc Gill Consenssus Meeting di Quebec Canada tahun Mei 2002, ${ }^{5}$ dinyatakan bahwa 2 implan yang mendukung overdenture merupakan pilihan pertama pada kasus rahang bawah tak bergigi. Salah satu contoh overdenture dengan dukungan 2 implan adalah pada kasus gigitiruan penuh overdenture dengan implan pada 33 dan 43 dan abutment berupa ball joint. Pada sistem ini dukungan diterima implan dan jaringan mukosa (Gambar 10).

Overdenture dengan menggunakan retensi magnet, bagian keeper menempel pada abutment dan magnet pada permukaan anatomis basis gigitiruan. $^{2}$

Implan intramukosa pada intramucosal insert-supported complete maxillary dentures dapat digunakan untuk mendukung gigitiruan penuh RA dan gigitiruan sebagian unilateral, baik untuk RA atau RB. Hal ini dilakukan terutama pada pasien yang sulit mendapatkan retensi untuk gigitiruan penuh di RA (gambar 11). ${ }^{3}$ 

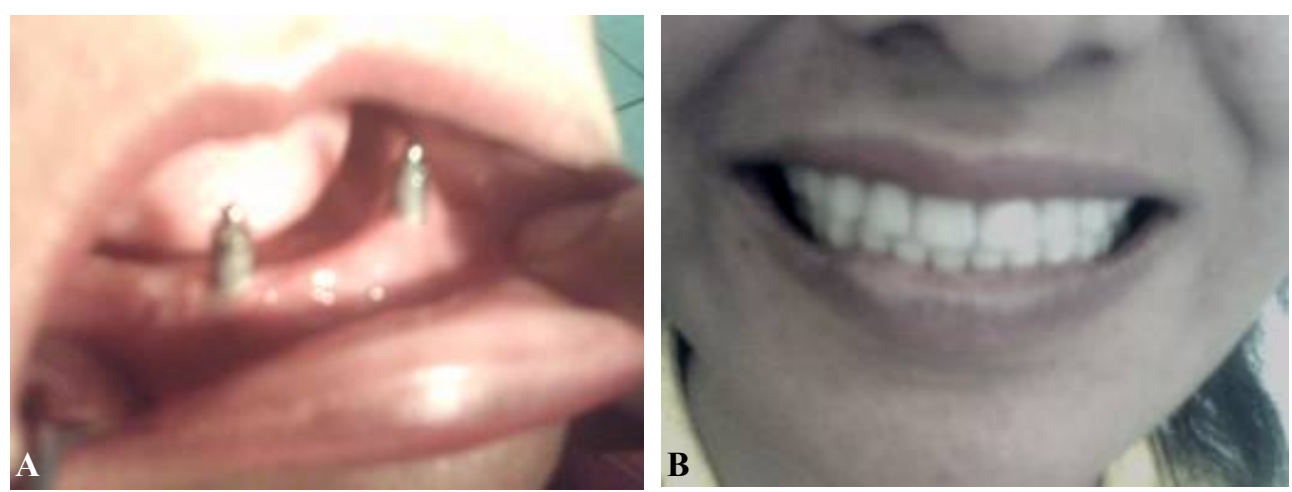

Gambar 10A Ball attachment, B. gigitiruan penuh terpasang dengan ball attachment

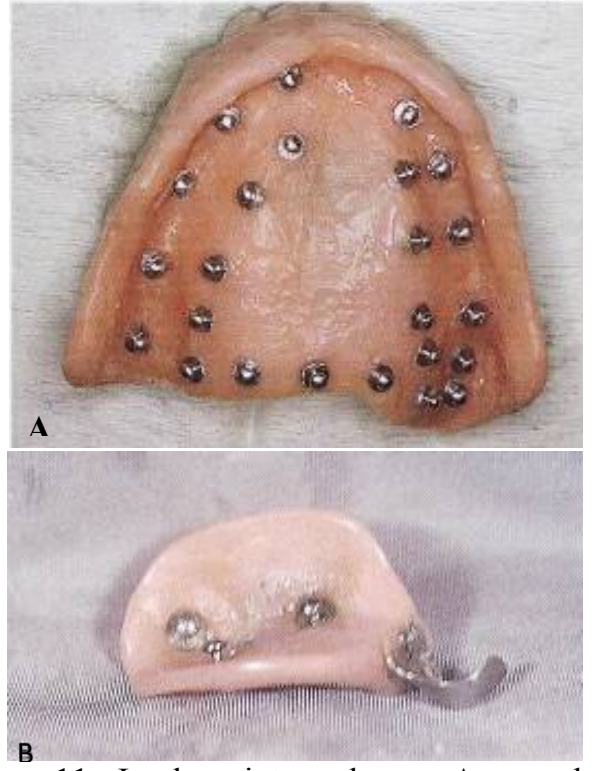

Gambar 11 Implan intramukosa; A mendukung gigitiruan penuh RA, B mendukung gigitiruan sebagian unilateral (Sumber: Singh PP, Cranin AN. Atlas of oral implantology. $3^{\text {rd }}$ Ed.; 2010. p. 59-67; 318-70). ${ }^{3}$
Dari hasil pembahasan dan telaah mengenai jenis-jenis gigitiruan dukungan implan, dapat disimpulkan bahwa penentuan macam gigitiruan yang akan dibuat di atas implan, dilakukan pada saat perencanaan perawatan, sebelum pemasangan implan. Telah diketahui ada tiga sistem pemasangan endosteal dental implant bentuk akar, yaitu sistem pemasangan dengan satu tahap, dua tahap, dan immediate restoration. Terdapat beberapa jenis gigitiruan yang dapat dipasangkan di atas implan, yaitu gigitiruan cekat dukungan implan meliputi single tooth implant restoration, single crown semi precision, fixed cementable prosthesis, fixed detachable prosthesis, dan hybrid bridge fixed detachable prosthesis.Sedangkan gigitiruan lepasan dukungan implan adalah overdenture, overdenture yang menggunakan ball attachment, overdenture dengan retensi magnet, intramucosal insertsupported complete maxillary denture, dan intramucosal insert-supported unilateral.

\section{DAFTAR PUSTAKA}

1. McCord JF. Missing teeth: A guide to treatment options.; 2003. p. 52-3.

2. Hobkirk JA. Introducing dental implants.; 2003. p. 29-65.

3. Singh PP, Cranin AN. Atlas of oral implantology. $3^{\text {rd }}$ Ed.; 2010. p. 59-67; 318-70.

4. Misch CE. Contemporary implant dentistry. $3^{\text {rd }}$ Ed.; 2008.

5. Branemark. Forty years of osseointegration. J Dental Asia 2005: 46-8.

6. Geering AH. Complete denture and overdenture prosthetics; 1993. p. 136-49. 